\title{
A evolução dos estudos sobre o integralismo
}

\author{
The evolution of studies about the Integralism
}

Rodrigo Santos de Oliveira*

Resumo: Pretendo fazer neste artigo um resgate da produção acadêmica sobre o integralismo, desde a fundação do movimento, com a Ação Integralista Brasileira (AIB - 1932-1937) e a rearticulação enquanto agremiação política, o Partido de Representação Popular (PRP - 1945-1965). Abordarei desde as primeiras pesquisas, desenvolvidas ainda nos anos de 1930 até o ressurgimento dos estudos sobre essa temática nos anos 1970 chegando nas pesquisas atuais.

Palavras-chave: Ação Integralista Brasileira, Partido de Representação Popular, Integralismo

Abstract: I intent to do in this paper a ramsom of the academic producion over the integralism, since the foundation of the movement, with the Brazilian Integralist Action (AIB - 1932-1937) and his rearticulation as political association, the Popular Representation Party (PRP - 1945-1965). I will brouches since the first researches, which were developed still in the early 1930's untill the resuscitation of the studies about this thematic in the 1970's to the present.

Keywords: Brazilian Integralist Action, Popular Representation Party, Integralism

O interesse acadêmico pelo movimento integralista teve seu início com a tese de doutoramento de Hélgio Trindade, defendida no ano de 1971 na Universidade de Paris, gerando intenso debate acadêmico nas Ciências Humanas, cujo reflexo é a grande quantidade de pesquisas realizadas sobre esta temática até os dias de hoje. Antes deste, havia apenas duas obras publicadas sobre Plínio Salgado e a Ação Integralista

* Professor do curso de Relações Internacionais da Faculdade América Latina/Caxias do Sul-RS. E-mail: <oliv.rod@terra.com.br>. 
Brasileira (AIB) - defendidas enquanto as "cinzas" do movimento ainda estavam quentes. Depois dessas pesquisas realizadas na segunda metade da década de 1930, o tema foi jogado no ostracismo acadêmico durante quase trinta anos. ${ }^{1}$ Nesse interregno o integralismo passou a ser visto como uma mera cópia caricata dos movimentos fascistas europeus e, essa simples afirmação por si só justificava qualquer resposta superficial sobre o integralismo. O objetivo deste artigo é fazer uma discussão sobre a evolução da produção acadêmica sobre o integralismo desde a década de 1930 até as pesquisas atuais.

\section{Os primeiros estudos acadêmicos ${ }^{2}$}

As primeiras pesquisas sobre o movimento integralista tiveram seu início ainda durante o período de vigência legal do movimento. No ano de 1937 Carlos Henrique Hunsche defendeu a tese de doutoramento O integralismo brasileiro: história do movimento fascista no Brasil ${ }^{3}$ na Faculdade de Filosofia da Universidade Friederich Wilhelm, Berlim. Este trabalho possui uma importância fundamental não apenas devido ao fato de ser a primeira análise acadêmica sobre o movimento (e portando "livre" das paixões políticas que faziam parte das disputas entre aqueles de defendiam e criticavam o integralismo), mas por representar uma leitura feita dentro da estrutura de um Estado organizado nos moldes fascistas (Alemanha Nazista). Contudo, não estamos afirmando que este trabalho seja uma leitura nazista sobre o integralismo, mas sim que o "meio" de certa forma "condicionou" o resultado final - como todo trabalho em Ciências Humanas os valores sociais da época e local influenciaram no desenvolvimento do mesmo. O autor não se coloca

1 Com a reestruturação do integralismo em agremiação política (Partido de Representação Popular) em 1945, o tema voltou a ser debatido na sociedade, principalmente pela vinculação ideológica da antiga AIB com o fascismo europeu. As discussões giravam em torno da legalização do partido. Contudo, isso não teve reflexo em estudos acadêmicos naquele período, ficando restrito aos espaços sociais e políticos.

2 Não levamos em conta o debate político e ideológico gerado nos anos de 1930, ou seja, entre aqueles que defendiam o movimento e aqueles que o combatiam. Entre os primeiros, seus principais representantes são os ideólogos integralistas, como Plínio Salgado, Gustavo Barroso, Miguel Reale, entre outros. Entre seus opositores, poderíamos citar: HERVÉ, Egydio. Democracia liberal e socialismo entre os extremos: integralismo e comunismo. Porto Alegre, Globo, 1935 e KONDER, Marcos. Democracia, Integralismo e Comunismo. Rio de Janeiro, 1935.

3 CALIL, Gilberto e SILVA, Carla (orgs). O Integralismo brasileiro: história e caráter do movimento fascista no Brasil, (tese de doutoramento autorizada pela Faculdade de Filosofia da Universidade Wilhelm, em Berlim, em 1930) de Carlos Henrique Hunsche. Porto Alegre, CD-AIB/PRP, 1996. Tradução de Leandro Silva Teles. 
como um crítico ou defensor do movimento, aliás, abstêm-se de emitir "juízos de valores" em seu texto. As críticas quando aparecem no corpo do texto são fundamentadas a partir da contraposição de fontes ou com comparações ao nazismo. ${ }^{4}$

Dividido em oito capítulos, o autor buscou compreender desde a influência autóctone da AIB - expresso no primeiro capítulo "A evolução do nacionalismo na História do Brasil", onde encontra o nacionalismo surgindo já com a chegada dos conquistadores portugueses em 1500, perpassando o Brasil colonial, imperial e republicano, tendo seu ápice com o integralismo e no quinto capítulo "A promoção da brasilidade", analisando a identificação que os integralistas apresentavam entre o movimento e a "brasilidade". Além dessa influência interna, o autor contrapõe com a externa, presente no segundo capítulo "A pré-história do movimento integralista" no contexto do pós-guerra e com os modelos políticos europeus e sua inter-relação com outros movimentos fascistas, presentes no sétimo capítulo "O Integralismo e os movimentos autoritários europeus". A mediação entre a influência interna e externa é tratada no terceiro capítulo "Os fundamentos ideológicos e o Integralismo brasileiro". 5 A organização do "Estado Integral" é abordado no quarto capítulo "O Estado Integralista". Um histórico da evolução do movimento é tratado no sexto capítulo "O crescimento da AIB" ${ }^{6} \mathrm{O}$ autor apresenta suas conclusões no oitavo capítulo, analisando o integralismo como um fenômeno ao mesmo tempo brasileiro, sulamericano e internacional.

Em 1938 Arnoldo Nicolau de Flue Gut defendeu a tese de doutoramento Plínio Salgado, o creador do integralismo brasileiro na literatura brasileira na Ludwig-Maximilian Universität de Munique. ${ }^{7}$

4 Um exemplo significante é a análise feita pelo autor no que se refere ao antissemitismo: "Na realidade, o antissemitismo de acordo com a Doutrina Integralista constitui um dos pilares básicos do Integralismo. Entretanto, seria um erro crasso traçar um paralelo entre o Nacional-Socialismo e o Integralismo no que concerne à problemática judaica, como faz a AIB para conquistar a população teuto-brasileira. O Nacional-Socialismo combate o judeu, antes de mais nada, fundamentado em sua concepção racial: como elemento destrutivo de uma raça. O Integralismo combate-o por razões políticas e econômicas”. Ibid., p. 81.

5 A questão da influência interna e externa do movimento integralista terá um papel de destaque no debate acadêmico surgido entre Hélgio Trindade, Gilberto Vasconcelos e José Chasin, discutido mais adiante.

$6 \mathrm{O}$ autor ainda traça previsões e possibilidades para o pleito previsto para 3 de janeiro de 1938 , tendo em vista que a tese fora entregue em junho de 1937, meses antes do golpe do Estado Novo, que fechou as agremiações políticas e impediu a realização das eleições presidenciais. Ibid., p. 107-108.

7 GUT, Nicolau de Flue. Plínio Salgado, o creador do integralismo na literatura brasileira. Speyer a. Rh., Pilger-Druckerei GmbH, 1940. 
Diferente da tese de Carlos Hunsche, que tem na AIB seu principal foco de análise, Gut centra suas atenções na obra intelectual de Plínio Salgado (tanto literária como política). Além da diferença de objeto de estudo a forma de abordagem entre os dois trabalhos será completamente oposta. Se por um lado, a análise de Hunsche é extremamente acadêmica, onde inclusive se omite de expressar juízo de valores, por outro, Gut não consegue manter a distância de seu objeto. Em vários momentos o autor deixa expressa sua simpatia pelo líder integralista, como por exemplo:

Quando, porém, a comoção toma conta da visão intelectual e esta se cristalizou em prismas regulares e transparentes, o ser, a alma de Plínio Salgado é um florilégio que se esbanja à vontade, inexorável: na poesia e na ciência. O pensamento é conciso, vibrante e de força irresistível. (GUT, p. 34.).

Critica Hunsche por ficar preso a uma análise meramente acadêmica, mantendo distância sentimental com seu trabalho: "Infelizmente, porém, o autor não se integrou com a alma brasileira, com o sentir brasileiro, com o pensamento central de Plínio Salgado" (GUT, p. 82). Critica também o fato do autor dar importância a influência da "lusitanidade"

No trabalho de Gut a AIB e a ideologia integralista ficam à margem, tendo muito pouco destaque. Embora cite uma série de obras de Salgado sobre o integralismo e jornais integralistas onde eram publicados os artigos do "Chefe Nacional", o conteúdo destes textos não é discutido (GUT, p. 31). Nos dois capítulos em que discute o pensamento político e o nacionalismo de Plínio Salgado (respectivamente capítulos IV - Plínio Salgado como pensador, e VI - Os últimos valores nacionalistas de Plínio Salgado), o autor, mesmo usando textos integralistas, não aborda o integralismo.

\section{$2 \mathrm{O}$ integralismo como novo tema de debate nas Ciências Humanas ${ }^{8}$}

Surgiu com a discussão em torno da tese de Trindade. Esse debate abriu espaço para uma verdadeira "onda" de estudos sobre o tema. Esses

8 Tendo em vista a grande quantidade de obras sobre o tema, não faremos uma análise exaustiva de toda a produção científica sobre a Ação Integralista. Buscaremos analisar algumas obras significativas e que sirvam para exemplificar as três fases desses estudos. 
estudos podem ser arbitrariamente divididos em três fases distintas: ${ }^{9}$ $1^{\text {a }}$ fase - a AIB como movimento de massas organizada nacionalmente; $2^{\mathrm{a}}$ fase - estudos regionais sobre o integralismo; $3^{\mathrm{a}}$ fase - novas abordagens sobre o integralismo.

\section{$1^{\mathrm{a}}$ Fase - A AIB como movimento de massas organizada nacionalmente $^{10}$}

A Ação Integralista Brasileira foi o tema central de uma série de estudos acadêmicos a partir dos anos de 1970. Uma das principais questões destes trabalhos era determinar quais eram suas origens ideológicas e a sua vinculação ou não com o fascismo, que a partir de sua matriz européia, se espalhou por várias regiões do planeta.

Tendo em vista o fato do movimento integralista ter apresentado como um dos elementos centrais de sua pregação política o nacionalismo e sempre ter defendido a originalidade de sua doutrina frente a influências externas, esta questão de influência ou não do fascismo sobre o integralismo foi um tema de discussão desses primeiros estudos.

9 É arbitrária, pois parte de uma divisão feita a partir de semelhanças presentes nesses trabalhos, ao mesmo tempo, não é uma separação fechada, existem trabalhos que poderiam ser enquadrados em mais de uma fase, devido às suas características. Em resumo, é uma divisão feita para uma melhor visualização da evolução das pesquisas sobre o tema. A idéia original dessa divisão foi apresentada no artigo a ser publicado nos anais do I Encontro de Pesquisadores do Integralismo ocorrido na cidade de Rio Claro em São Paulo, nos dias 16 e 17 de outubro de 2002. Havíamos originalmente apresentado o termo gerações para caracterizar essas pesquisas, no entanto, preferimos alterar para o termo fases, pois gerações acabaria por marcar os trabalhos de acordo com o período em que foram produzidos e não devido ao seu conteúdo, que, em nossa opinião, é o que diferencia uma fase de estudo de outra.

${ }^{10}$ Não analisaremos individualmente as obras de Trindade, Vasconcelos e Chasin, principais representantes desta primeira fase, pois tais obras já foram amplamente discutidos em outros trabalhos. Escolhemos então analisar um ponto específico e que tenha sido discutido pelos três autores, ou seja, analisaremos um possível diálogo entre os três autores. Além da discussão feita por intelectuais brasileiros, o tema também foi objeto de pesquisa de três autores norte-americanos: LEVINE, Robert M. O regime Vargas. Os anos críticos (19341938). Rio de Janeiro: Nova Fronteira, 1980 (a versão original em inglês foi publicada em 1970); BROXSON, Elmer. Plínio Salgado and the Brazilian Integralism (19321938). Washington: The Catholic University of América, 1972 (tese de doutorado - não tivemos acesso a esse trabalho ainda); HILTON, Stanley. A Ação Integralista Brasileira: fascism in Brazil (1932-1938). In: O Brasil e a Crise Internacional (1930/1945). Rio de Janeiro: Civilização Brasileira, 1977 (a versão original em inglês publicada em 1972). O integralismo ainda foi discutido no estudo sobre o fascismo de Stanley Payne, em que o integralismo brasileiro é apresentado como "El único que alcanzó real importancia y que, de hecho, se convirtió em el único gran partido latinoamericano que se aproximara en casi todos los aspectos al fascismo europeo, fue la Ação Integralista Brazileira de Plínio Salgado, fundada em 1932”. PAYNE, Stanley G. Historia del fascismo. Barcelona: Editorail Planeta, 1995. 
Nesta parte faremos uma análise deste debate, surgido entre Hélgio Trindade (Integralismo: o fascismo brasileiro na década de 30), Gilberto Vasconcelos (Ideologia curupira: Análise do discurso integralista) e José Chasin (O integralismo de Plínio Salgado). ${ }^{11}$

Ao ler o trabalho dos três autores fica claro que a formação ideológica inicial de Plínio Salgado se dá nos anos de 1920, principalmente em sua atuação literária "verde-amarela" da Semana de Arte Moderna e na frustrada atividade partidária no Partido Republicano Paulista (frustrada segundo a própria leitura de Salgado).

Mesmo que a formação política de Plínio Salgado nos anos de 1920 seja um ponto pacífico para os autores, a influência dessa base ideológica sobre a futura AIB será diferente para cada um.

A explicação mais controversa ao nosso ver é a de José Chasin. Para o autor a base da futura AIB estaria assentada sobre três "pilares fundamentais" (capítulo II - Véspera e antevéspera de um movimento). ${ }^{12}$ O primeiro seria a atuação literária de Plínio Salgado. O segundo seria a atuação política dentro do Partido Republicano Paulista (PRP). A experiência resultante dos dois primeiros "pilares" abriria as portas para o terceiro, que seria a doutrinação jornalística, a partir do jornal $A$ Razão, fundado em 1931, após o retorno de Plínio Salgado da Europa. Ao

11 TRINDADE, Hélgio. Integralismo: o fascismo brasileiro na década de 30. São Paulo: Difel, 1974; VASCONCELOS, Gilberto. Ideologia Curupira: análise do discurso integralista. São Paulo: Brasiliense, 1979; CHASIN, José. O integralismo de Plínio Salgado: forma de regressividade no capitalismo hiper-tardio. São Paulo: Livraria Editora Ciências Humanas, 1978. Em realidade o diálogo de Vasconcelos e Chasin não foi o primeiro debate acadêmico enfrentado por Hélgio Trindade. O primeiro se estabelecerá a partir das críticas feitas por Wanderley Guillherme dos Santos na obra "Paradigma e História - a ordem burguesa na imaginação social brasileira" (Rio de Janeiro, FGV, 1975). Não tivemos acesso a esse trabalho até o presente momento, contudo, possuímos a réplica de Trindade, publicada na Revista do Instituto de Filosofia e Ciências Humanas da Universidade Federal do Rio Grande do Sul (Porto Alegre, v. 4, 1976, p. 126-134), sob título de "Texto e Contexto: nota crítica a alguns aspectos do estudo 'Paradigma e História' de Wanderley Guilherme dos Santos". A crítica de Trindade ao trabalho se baseia no fato do autor utilizar trechos descontextualizados do livro Integralismo (o fascismo brasileiro dos anos de 30) como justificativa para apontar supostas falhas desta obra. Como aponta Trindade em relação às críticas feitas sobre a simpatia de Plínio Salgado ao fascismo europeu: "E o sintomático é que, do conjunto de citações de Salgado, o autor escolhe a menos explicitamente simpática ao fascismo europeu. Ele não menciona as referências feitas em dois ou três parágrafos anteriores em que Salgado afirmava, por exemplo, que 'o fascismo é o Estado-síntese por excelência, o Estado que traz em si, todas as fisionomias nacionais' ou, mais adiante, que 'o que há de essencial na doutrina fascista é perfeitamente aceitável, como concepção de Estado"” (p. 131). E assim por diante, seguem as críticas em que Trindade afirma que o autor extrapola ilegitimamente o significado do seu texto.

12 CHASIN, p. 177-489. 
mesmo tempo, o autor renega veementemente uma possível influência do fascismo europeu na formação do movimento integralista.

A leitura de Vasconcelos sobre as influências para a formação da AIB diverge das propostas por Chasin. Segundo o autor, os principais elementos da doutrina integralista estariam presentes, mesmo que de forma rudimentar na corrente "verdeamarela" e "Anta" do modernismo dos anos de 1920. Contudo, as influências do fascismo dariam o "norte" para a organização do integralismo.

Para Trindade, por sua vez, a formação política de Plínio Salgado nos anos de 1920, tanto literária como no PRP, são necessárias para compreender a formação da Ação Integralista, contudo, o contexto do fascismo é decisivo para definir a natureza da ideologia integralista.

Aparentemente o fio condutor das críticas de Chasin está expresso no segundo parágrafo da sua introdução, quando afirma que há uma oposição entre Plínio Salgado, que defendia que sua ideologia era autóctone, baseada em uma raiz brasileira e não européia (e distinta do fascismo) enquanto os críticos ao integralismo, esquecendo ou renegando o que afirmava o líder integralista, defendem o contrário, que o discurso de Salgado em vez de original é o resultado de meras dissimulações táticas. As críticas feitas por tais autores (no caso o autor cita Trindade e Edgar Carone) procuram explicar o integralismo a luz do mimetismo, ou seja, defendem à influência externa, principalmente da matriz fascista européia. O autor refuta tais idéias ao fazer uma análise da tese de doutoramento de Hélgio Trindade. Defende, de forma veemente, o integralismo como resultado da atuação e das experiências políticas de Plínio Salgado e a desvinculação do pensamento integralista do fascismo europeu.

O trabalho de Trindade, duramente criticado por Chasin - ao nosso ver críticas de forma bastante superficiais -, apresenta dados mais coesos e concisos. O integralismo segundo a interpretação de Trindade, não é um mero mimetismo como Chasin apresentou em sua crítica. Em realidade, difere completamente. Em nenhum momento o autor afirma uma transposição direta da ideologia fascista para o Brasil ou renega as influências prévias de Plínio Salgado, pelo contrário, vai além, explora essas influências, só que sem a preocupação de utilizá-las para comprovar suas hipóteses, mas como um complemento para a sua análise. $\mathrm{O}$ integralismo, visto por Trindade não é uma cópia caricata, ou um mero fascismo "tupiniquim". Mais do que isso é um movimento que possui influências do fascismo, contudo mantém suas peculiares frente 
ao fascismo italiano, alemão etc. Ao mesmo tempo, o autor não se prende apenas a Plínio Salgado, explora outros autores do movimento, o que contribui para uma visão mais ampla, mais geral e menos generalizante como a de José Chasin.

Não é possível avaliar as críticas de Chasin a Vasconcelos (e viceversa), tendo em vista que os autores não se citam mutuamente. Os dois trabalhos foram defendidos mais ou menos no mesmo período em diferentes cursos de pós-graduação e provavelmente não tiveram conhecimento recíproco até sua conclusão. Contudo, tendo em vista os enfoques opostos dos seus trabalhos, podemos chegar a uma aproximação do que seria a crítica. Provavelmente a principal seria a forma heterodoxa de Vasconcelos para explicar o integralismo. Indo das bases ideológicas do movimento dentro da corrente "verdeamarela" no modernismo, até a influência do fascismo, o autor busca apoio teórico não apenas na História Política, mas também no marxismo, em obras literárias, na psicanálise etc. Além disso, o autor não nega a influência do fascismo. Ao mesmo tempo, as críticas de Vasconcelos provavelmente estariam centradas no "determinismo" de Chasin em procurar "comprovar" a originalidade do integralismo frente a ideologias externas. Também criticaria a ortodoxia de utilizar apenas a produção de Plínio Salgado para explicar o fenômeno do movimento integralista.

As críticas de Hélgio Trindade tanto a Vasconcelos quanto a Chasin foram sistematizadas na coletânea "História Geral da Civilização Brasileira". ${ }^{13}$ No que concerne as críticas dirigidas à Ideologia Curupira, Trindade aponta certas generalizações feitas pelo autor, como por exemplo: apontar influências do fascismo no discurso ideológico, mas não exemplificá-lo com fontes; utilizar apenas textos de Plínio Salgado, esquecendo de outros autores como Gustavo Barroso e Miguel Reale e sua influência no movimento. Contudo, o conjunto da análise sobre a obra feita por Trindade, apesar de considerar "polêmica em função da diversidade de enfoques analíticos utilizados para captar multiformes dimensões do discurso pliniano", não nega a contribuição feita pelo autor, ao contrário, a coloca como uma obra original sobre a interpretação do discurso integralista.

Em relação à obra de José Chasin as críticas foram mais duras, citaremos apenas as principais. Para o autor o trabalho de Chasin já

\footnotetext{
13 TRINDADE, Hélgio. Integralismo: teoria e práxis política nos anos 30. In: FAUSTO, Boris (org.). História Geral da Civilização Brasileira - O Brasil Republicano, Sociedade e Política (1930-1964). São Paulo: DIFEL, 1981, vol. 3, p. 304-316.
} 
parte de um determinismo que atrapalha toda a sua obra: que só existiria o fascismo no Brasil se o capitalismo tivesse tido um estágio superior. Para comprovar tal premissa, o autor utilizou apenas a produção de Plínio Salgado na sua tese de que o integralismo não possui influência do fascismo, defendendo, inclusive, a visão "oficial" de Salgado de que o integralismo teria sido uma ideologia baseada em elementos puramente brasileiros. Para Trindade, um dos principais problemas metodológicos de Chasin foi ter utilizado textos não apenas dos anos de 1930 (1932-1937, período de vigência da AIB), mas também obras do pósguerra. $\mathrm{O}$ ponto central dessa questão em utilizar indiscriminadamente textos do pós-guerra está na adulteração sofrida no período de redemocratização, quando as obras sofreram alterações para renegar o caráter fascista e antidemocrático da extinta AIB, alvo principal daqueles que se opunham à reestruturação do integralismo como partido político. Assim, mais uma vez Chasin estaria defendendo o ponto de vista "oficial" dos integralistas.

Com base na leitura das obras dos autores e também no debate gerado por suas análises podemos fazer algumas considerações em torno da questão fundamental desse debate inicial: o integralismo é uma ideologia do "sertão" ou do "litoral"?

Ao nosso ver a resposta mais aproximada para a questão seria ambos, pois embora haja as influências iniciais de Plínio Salgado nos anos de 1920 (o que de certa forma inicia sua visão nacionalista e ufanista de ver o Brasil), as influências do fascismo europeu são inegáveis, tendo em vista a estruturação do movimento e seus pressupostos políticos.

Aliás, como todo movimento fascista ou semifascista, as características locais influem no "resultado final", para tanto basta ver as diferenças entre o fascismo italiano e o nazismo ou ainda entre o salazarismo e o franquismo. A AIB como sendo um movimento com influências do fascismo não foge dessa regra: se por um lado possui semelhanças com outros movimentos de orientação fascista (partido único, corporativismo, anticomunismo e antiliberalismo etc.), por outro possui características que lhe são peculiares (espiritualismo, apelo religioso etc.).

Assim, acreditamos que seja difícil caracterizar a Ação Integralista Brasileira (e a própria atuação de seus membros) como uma ideologia do "sertão" ou do "litoral". Possui elementos de ambos, como os trabalhos de Vasconcelos e Trindade comprovaram. A leitura realizada por Chasin, como já apontamos, apresenta uma série de problemas, principalmente 
por partir do determinismo de negar a influência do "litoral" na ideologia integralista. ${ }^{14}$

\section{$2^{\text {a }}$ Fase - O integralismo organizado regionalmente}

Em um artigo de jornal publicado em 1978, Trindade ${ }^{15}$ destacava as diferenças entre as abordagens dos principais estudos até então defendidos sobre a AIB (no caso entre a sua tese de doutoramento, a de Gilberto Vasconcelos -Ideologia Curupira - e principalmente com a de José Chasin - O integralismo de Plínio Salgado). No mesmo artigo também apresentou um trabalho que fugia do "modelo" original dessas pesquisas: Os Teuto-Brasileiros e o Integralismo no Rio Grande do Sul, dissertação de mestrado de René Gertz, ${ }^{16}$ que trazia para a discussão elementos sobre a AIB de cunho regional, em contraposição aos trabalhos que estudavam o movimento organizado nacionalmente, que havia sido a característica principal da "primeira fase".

A dissertação de Gertz desencadeou uma onda de estudos regionais - tendo em vista que os primeiros estudos não conseguiram (ou não pretenderam) dar conta da estruturação do movimento integralista nas diversas regiões do país, ficando apenas em uma discussão do movimento enquanto nacional - havia uma grande lacuna sobre as peculiaridades de cada região. O integralismo seria igual em São Paulo, Rio de Janeiro, Minas Gerais, Ceará, Rio Grande do Sul, etc, ou teria diferenças? Embora ainda não exista nenhum trabalho que procure sistematizar uma comparação entre diferentes regiões do país, a leitura desses trabalhos regionais nos permite notar diferenças e semelhanças na estruturação regional do movimento integralista, que nos permite compreender melhor o funcionamento e também a própria atuação e inserção dos integralistas na sociedade brasileira dos anos de 1930.

${ }^{14}$ A discussão desta fase sobre o integralismo organizado nacionalmente não foi esgotada nos anos de 1970, sendo retomada posteriormente em SOUZA, Francisco Martins de. O integralismo. In: Curso de introdução ao pensamento político brasileiro. Unidade IX e X. Brasília: Editora da UNB, 1982; e ARAÚJO, Ricardo Benzaquen de. Totalitarismo e Revolução. O integralismo de Plínio Salgado. Rio de Janeiro: Jorge Zahar, 1988. O autor ainda realizou dois estudos sobre os líderes integralistas Plínio Salgado e Miguel Reale: A cor da esperança-totalitarismo e revolução no integralismo de Plínio Salgado. Rio de Janeiro: CPDOC/FGV, 1984 (não tivemos acesso a esse trabalho ainda); In Medio Vertius: uma análise da obra integralista de Miguel Reale. Rio: CPDOC/FGV, 1988.

15 TRINDADE, Hélgio. Integralismo e Fascismo em questão. Zero Hora, Porto Alegre, 9/4/1978, p. 12.

${ }^{16}$ GERTZ, René. Os Teuto-Brasileiros e o Integralismo no Rio Grande do Sul. Contribuição para a interpretação de um fenômeno político controvertido. Porto Alegre: UFRGS, 1977 (dissertação de mestrado em Ciência Política). 
A dissertação de Gertz não teve a pretensão de ser um estudo sobre o integralismo no estado do Rio Grande do Sul, como o próprio título sugere, visava analisar a relação entre o integralismo e os teuto-brasileiros, grupo étnico em que o movimento integralista teve considerável inserção social. $\mathrm{O}$ trabalho dividido em três partes apresenta uma discussão sobre germanismo ${ }^{17}$; germanismo e nazismo; germanismo e integralismo e integralismo e nazismo na primeira parte. A segunda parte dedica-se ao estudo dos teuto-brasileiros e a política sul-riograndense. O estudo de caso da comunidade étnica teuto-brasileira de São Leopoldo é o tema da terceira parte.

$\mathrm{O}$ autor aprofunda a pesquisa em sua tese de doutoramento, ${ }^{18}$ expandindo seu recorte físico ao estado de Santa Catarina. Além de aumentar seu espaço de pesquisa, também acrescenta novas perguntas, como a questão da imigração alemã e sua relação com a política regional, e a participação dos teutos na política tanto imperial como republicana (República Velha), apresentado no primeiro capítulo. Discute de forma mais aprofundada a questão do nazismo e os teuto-brasileiros, além das relações entre Brasil e Alemanha no período e as intenções do nazismo no Brasil. No terceiro capítulo sistematiza a relação entre o integralismo e os teutos no Rio Grande do Sul e Santa Catarina.

Ambos os trabalhos apresentam um dado peculiar no que se refere ao integralismo: o integralismo até então era considerado como um movimento puramente urbano, principalmente a partir de sua matriz paulista e carioca, não havendo muita inserção nas zonas rurais. No sul do país, em contrapartida, houve considerável influência nas regiões coloniais (tanto rurais como urbanas).

Assim como os trabalhos de Gertz, que trouxeram a discussão do integralismo para os teuto-brasileiros no sul do Brasil, a tese de Josênio Parente ampliou a discussão do integralismo para o Nordeste, mais especificamente para o caso do Ceará. ${ }^{19}$ A peculiaridade deste trabalho está centrada em dois pontos básicos: movimento operário/integralismo

${ }^{17}$ Segundo o autor, germanismo ou "Deutschtum", era um “[...] movimento [que] tinha por objetivo garantir a peculiaridade étnico-cultural de todos os alemães e seus descendentes no Brasil, tentando segregá-los deliberadamente da população etnicamente diferente que aqui habitava". Ibid., p. 16.

${ }^{18}$ Utilizamos aqui a publicação da tese em português: O fascismo no sul do Brasil. Porto Alegre: Mercado Aberto, 1987.

19 PARENTE, Josênio. Os camisas verdes no poder. Fortaleza: Edições UFC, 1986. No mesmo ano foi publicado MONTENEGRO, J.A.S. O integralismo no Ceará. Fortaleza, 1986. Até o presente momento não tivemos acesso a esse trabalho. 
e Igreja Católica/integralismo, tendo como elo de ligação a Legião Cearense do Trabalho (LCT).

Do mesmo modo que Rio Grande do Sul e Santa Catarina, o Ceará estava distante do "centro" de difusão ideológica da Ação Integralista Brasileira: São Paulo e Rio de Janeiro. Apesar dessa distância, o Estado do Ceará foi o responsável pela maior vitória eleitoral do movimento: com apoio da Liga Eleitoral Católica (LEC) ${ }^{20}$ elegeu um deputado federal em 1933 (Jeovah Motta) e dois estaduais em 1934 (Ubirajara Índio do Ceará e Carlito Benevides). Isso garantiria a participação direta dos integralistas no Governo do estado em 1935, devido ao auxílio dos deputados integralistas na eleição indireta do governador do estado (Francisco Menezes Pimentel) e dos dois senadores (Edgar de Arruda e Waldemar Falcão), que eram membros da LEC. ${ }^{21}$

Igualmente peculiar foi a grande inserção do integralismo junto ao movimento operário do Ceará. Um fato que chama a atenção, devido à pouca influência dos camisas-verdes nos círculos operários de outras regiões do país. A incorporação da LCT pela AIB garantiu essa grande influência junto aos operários e ainda possibilitou estabelecer amistosa relação com a Igreja Católica, tendo em vista que essa possuía grande poder junto aos operários cearenses.

Os trabalhos anteriores, baseados em dados gerais apontavam para um distanciamento entre o operariado e a AIB, além de um afastamento dos círculos de poder. A partir do estudo de Parente, esses dados precisam ser relativizados, tendo em vista que, no caso específico do Ceará, a regra geral não pode ser aplicada, pois o integralismo nesse estado teve grande repercussão junto aos operários e, ao mesmo tempo, teve participação direta no círculo central do poder. ${ }^{22}$

A obra Integralismo e política regional: a ação integralista no Maranhão de João Ricardo de Castro Caldeira ${ }^{23}$ complementa a

20 "Formada por inspiração do Cardeal Leme, do Rio de Janeiro, a LEC marcou a presença política da Igreja Católica na sociedade brasileira. Pretendia influir na eleição para a Assembléia Nacional Constituinte, as Assembléias Legislativas e as Câmaras Municipais". PARENTE, p. 15.

${ }^{21}$ Ibid. p. 141.

${ }^{22}$ No mesmo ano da obra de Parente foi publicado o livro Pequena História do Integralismo no RN de Luiz Gonzaga Cortez (Natal: Clima/Fundação José Augusto, 1986). Em forma de narrativa, desprendido de qualquer estrutura acadêmica, o trabalho restringiu-se a relatar fatos ocorridos no estado do Rio Grande do Norte, não utilizando nenhum referencial teórico sobre o integralismo, com exceção de uma breve citação à tese de Hélgio Trindade em uma nota de rodapé, não sendo citado posteriormente na bibliografia (p. 55).

${ }^{23}$ CALDEIRA, João Ricardo de Castro. Integralismo e política regional: a Ação Integralista Brasileira no Maranhão. São Paulo: Annablume, 1999. 
produção de obras regionais sobre o integralismo. Traz histórico do desenvolvimento e evolução da Ação Integralista no estado do Maranhão. Dividido em três capítulos, que contemplam a evolução cronológica do movimento, aborda a estruturação do movimento e o início de sua consolidação com a eleição de 1934 para a Câmara Federal e a Assembléia Constituinte do estado ${ }^{24} \mathrm{em}$ seu primeiro capítulo. A oposição à ANL e ao comunismo no Maranhão é o tema do segundo capítulo, que trata da expansão do integralismo no ano de 1935. O terceiro e último capítulo aborda o auge da AIB local e o seu fechamento. Nessa parte é tratada a relação da AIB com seus aliados e adversários e a organização dos exmembros no contexto posterior ao fechamento da AIB.

$\mathrm{O}$ trabalho de Caldeira, assim como os demais trabalhos regionais, nos mostram que as características locais foram decisivas para as formas de inserção social e a conquista de espaços pelos integralistas - o que reflete uma "quebra" com a imagem idílica de ordem e unificação, na qual os integralistas têm de conquistar ou negociar seus espaços, como ficou evidente no estudo de Gertz ${ }^{25}$ e no de Parente. ${ }^{26}$

Até o presente momento dos estudos regionais - pelo menos das obras de que temos conhecimento -, apenas as regiões periféricas apresentam estudos sistemáticos sobre a organização do integralismo. Talvez isso se deva ao fato de que durante os debates iniciais, indiretamente os núcleos centrais do movimento integralista - São Paulo, Rio de Janeiro e em menor grau Minas Gerais - eram tidos como matrizes de difusão da ideologia e do movimento. Contudo, essa interpretação é insuficiente para explicar a inexistência de tais trabalhos, principalmente se levarmos em conta que o integralismo nesses Estados não ficou restrito às capitais, tendo se expandido para o interior, e, se levarmos em conta outros exemplos regionais em que o integralismo apresentava significativas diferenças entre capital e interior (e às vezes entre regiões e cidades próximas), há uma grande lacuna nos estudos regionais que ainda necessitam ser pesquisados.

${ }^{24}$ Os integralistas não elegeram nenhum dos seus candidatos, contudo, se levarmos em conta a organização necessária para concorrer a uma eleição, isso reflete em uma organização considerável. Ibid., p. 40-48.

${ }^{25}$ No caso o autor apresenta a leitura do Pastor Hermann Dohms sobre o integralismo em uma série de artigos publicados na revista mensal DEBB entre 1933 e 1936. Em uma citação apresenta resposta de Wolfram Metzler, líder integralista, sobre a questão do uso da língua alemã e a manutenção das associações culturais germânicas. Nesse exemplo fica expressa a possibilidade de negociação. GERTZ, 1977, p. 29-33.

${ }^{26}$ No caso sobre as negociações que levaram à eleição de deputados integralistas e a participação no governo e à inserção no movimento operário local e o bom relacionamento com o clero local, já citado anteriormente. 
A partir dos anos de 1990 surge uma grande quantidade de estudos sobre o movimento integralista no Rio Grande do Sul. ${ }^{27}$ Em um recente artigo Gertz faz uma análise da evolução dessas pesquisas e o seu destaque no bojo das discussões regionais. ${ }^{28}$ Tendo em vista que o autor, de forma sintética, deu conta do tema não iremos fazer uma profunda leitura desses trabalhos, nos limitaremos a fazer uma citação pontual de algumas das principais obras.

O primeiro trabalho que procurou sistematizar a questão do integralismo no Rio Grande do Sul é a dissertação de Carla Brandalise ${ }^{29}$, que traça um panorama geral da estruturação da AIB no Rio Grande do Sul. Embora dê ênfase às zonas de colonização italiana, procura fazer comparação com a zona de colonização alemã.

A questão do integralismo na zona de colonização italiana é retomada posteriormente por Daniela Pistorello, ${ }^{30}$ dando ênfase principalmente à região de Caxias do Sul. A questão do integralismo na região norte do Estado é o tema do trabalho de Fausto Irschlinger ${ }^{31}$, zona com grande concentração de teuto-brasileiros, em alguns pontos retoma a discussão iniciada por Gertz.

O grau de especificidade chegou a tal estágio que novos trabalhos apresentaram um recorte espacial mais restrito, ao invés de regiões, municípios. Como é o caso da dissertação mestrado de Ivo Canabarro dos Santos $^{32}$ sobre o integralismo na cidade de Ijuí. Essa pesquisa apresenta

${ }_{27}$ Esses novos estudos regionais surgem na mesma época em que novas perguntas começam a ser feitas nas Ciências Humanas, tendo reflexo nos trabalhos sobre o integralismo, muitos dos trabalhos abaixo poderiam ser também enquadrados na terceira "fase", discutido adiante.

${ }^{28}$ GERTZ, René. O integralismo no Rio Grande do Sul. In. Jornal Folha da História. Porto Alegre, novembro de 2002, ano VII, n. 61, p. 7 (edição especial sobre os setenta anos do surgimento do integralismo).

${ }^{29}$ BRANDALISE, Carla. O fascismo na periferia latino-americana: paradoxo da implantação do integralismo no Rio Grande do Sul. Porto Alegre, UFRGS, 1992 (dissertação de mestrado em Ciência Política).

30 PISTORELLO, Daniela. “Os homens somos nós”: O integralismo na região colonial italiana do Rio Grande do Sul. Porto Alegre: PUCRS, 2001 (dissertação de mestrado em História). Além da atuação do integralismo na zona de colonização italiana, há a intervenção do fascismo italiano, discutido de forma rápida por Pistorello. É o tema do trabalho de: GIRON, Loraine Slomp. As Sombras do Littorio: o fascismo no Rio Grande do Sul. Porto Alegre: Parlenda, 1994. A crítica deste trabalho aparece em: BERTONHA, João Fábio. Entre a bombacha e a camisa preta: notas sobre a ação do fascismo e do integralismo no Rio Grande do Sul. Estudos Ibero-Americanos/Pós-Graduação em História. Porto Alegre: EDIPUCRS, ano 24, n. 2, dezembro de 1998.

${ }^{31}$ IRSCHLINGER, Fausto Alencar. Perigo Verde: o integralismo no norte do Rio Grande do Sul (1932-1938). Passo Fundo: UPF, 2001.

32 CANABARRO, Ivo dos Santos. Uma abordagem cultural de um movimento político dos anos trinta: o caso do integralismo em Ijuí. Porto Alegre: UFRGS, 1994 (dissertação de mestrado em História). 
uma nova abordagem sobre o integralismo, uma visão mais voltada para o cultural do que para o político sob o prisma da Nova História Cultural. Outro trabalho cujo recorte é municipal é a dissertação de Daniel Milke ${ }^{33}$ sobre o integralismo em Porto Alegre. Sob o prisma da Nova História Política, traça a trajetória da AIB na capital gaúcha desde sua gênese, sua evolução e conseqüente perseguição a partir de sua organização interna, combate aos inimigos, busca de espaços, relação com aliados, intervenção política, etc.

Atualmente não apenas o integralismo nos municípios passou a ser tema de estudos como também o estudo sobre lideranças integralistas locais como Dario de Bittencourt e Wolfram Metzler. Maria Barreras ${ }^{34}$ traçou um interessante estudo sobre o "Chefe Provincial" Dario de Bittencourt, analisando não apenas o período em que foi membro da AIB como também toda sua intervenção política nas décadas de 1920 até seu falecimento em 1974. A atuação política do teuto-brasileiro Wolfram Metzler é o tema do trabalho de Veridiana Tonini. ${ }^{35}$ Partindo do "microcosmo" central (Metzler), a autora traça importantes relações entre integralismo (tanto no período da AIB como no PRP), política regional, Igreja Católica e as regiões coloniais do Rio Grande do Sul.

\section{$3^{\text {a }}$ Fase - Novas abordagens sobre o integralismo}

Durante a década de 1990 os estudos sobre o integralismo ganharam um verdadeiro impulso. Este passou a ser visto segundo diversos matizes, as perguntas mudaram. A escolha dos temas foram do "porão" ao "sótão", em uma alusão ao clássico estudo de Peter Burke sobre a Escola dos Annales. ${ }^{36}$ No primeiro momento buscavam compreender a AIB a partir da organização nacional e do pensamento das principais lideranças nacionais como Salgado, Barroso e Reale. Esse paradigma começou a ser quebrado com os estudos regionais, onde ficou claro que as questões locais interferiam na forma de intervenção do integralismo junto à sociedade, e essa discussão regional acabou por suscitar novos

${ }_{33}$ MILKE, Daniel Roberto. O integralismo na capital gaúcha: espaço político, receptividade e repressão (1934-1938). Porto Alegre: PUCRS, 2003 (dissertação de mestrado em História)

${ }^{34}$ BARRERAS, Maria José Lanziotti. Dario de Bittencourt (1901-1974): uma incursão pela cultura política autoritária gaúcha. Porto Alegre: PUCRS, 1993 (dissertação de mestrado em História).

35 TONINI, Veridiana M. Uma relação de amor e ódio: o caso Wolfram Metzler (1932-1957). Passo Fundo, UPF, 2003.

${ }^{36}$ BURKE, Peter. A Escola dos Annales: a revolução francesa da historiografia. São Paulo: UNESP, 1997. 
questionamentos, que caracterizariam uma nova "fase" de estudos. Essa terceira "fase" tem buscado dar conta de uma série de temas que possuíam um papel marginal nas discussões iniciais e passaram a ter relevância, cujo estudo nos permite compreender de forma mais clara o funcionamento do integralismo: o militante de base ganhou voz, a mulher integralista também, a intervenção do integralismo junto à sociedade passou a ter relevância, os símbolos e ritos passaram a ser estudados, integralismo no pós-guerra se tornou objeto de estudo, o combate aos inimigos do integralismo também, e assim por diante.

Atualmente há um interessante intercâmbio entre os pesquisadores que estudam o integralismo, a partir de uma lista de discussão na internet chamada Grupo de Estudos do Integralismo (GEINT). ${ }^{37}$ A partir dos contatos do GEINT já foram organizados dois encontros nacionais de pesquisadores do integralismo, o primeiro realizado na cidade de Rio Claro em São Paulo, no mês de novembro de 2002, e o segundo na cidade de Porto Alegre no Rio Grande do Sul, no mês de outubro de 2003. Esses encontros têm mostrado a grande variedade de estudos sob os mais variados enfoques e temas, o que revela a grande riqueza desta terceira "fase". ${ }^{38}$

Embora tenhamos afirmado que essa terceira "fase" tenha iniciado nos anos 1990, uma publicação feita ainda nas discussões iniciais da década de 1970 apresentou questionamentos que viriam ser amplamente discutidos posteriormente. Nos referimos ao texto "Apontamentos para uma crítica da Ação Integralista Brasileira” de Marilena Chauí. Esse trabalho discute o integralismo como organização política nacional, semelhante ao de Trindade, Vasconcelos e Chasin, contudo, fica explícita a insatisfação da autora com as explicações sobre a AIB presentes nesses estudos. Para isso - e aqui fica o diferencial de seu trabalho - propõe novas abordagens, seja uma nova forma de interpretar a questão da ideologia, que permeia toda a obra, seja pela questão do imaginário integralista, ou o destinatário do discurso. Ou seja, sua discussão se insere no contexto da primeira "fase", mas suas questões se aproximam daquilo que posteriormente será discutido em pontos mais específicos da terceira "fase".

${ }^{37}$ Endereço na internet: geint@yahoogrupos.com.br

38 O Terceiro Encontro de Pesquisadores do Integralismo ocorrerou na cidade de Ponta Grossa, no Paraná, em novembro de 2005. Este Encontro está em nota e não no corpo do texto pois durante a redação do presente texto ele ainda não ocorreu e na data da publicação sim. 
Mas esses questionamentos só começaram a ganhar fôlego nos anos de 1990. O primeiro destes surgiu em torno da questão do antissemitismo dentro do movimento integralista, mais especificamente de sua principal matriz ideológica, Gustavo Barroso. Durante o debate dos anos de 1970, o antissemitismo, assim como o combate aos demais inimigos declarados do movimento, recebeu explicações superficiais em notas de rodapé ou pequenos trechos de capítulos, insuficientes para explicar esse fenômeno. Tendo em vista essa lacuna dois autores se debruçaram sobre a obra de Barroso: Roney Cytrynowicz ${ }^{39}$ e Marcos Chor Maio. ${ }^{40} \mathrm{~A}$ importância desses trabalhos reside no fato de abrirem perspectivas de pesquisa a temas considerados "secundários", além, é claro, de analisar a questão do antissemitismo.

A questão da memória dos militantes é abordada por Márcia Carneiro. ${ }^{41}$ Tem o mérito de reconstruir o cotidiano da militância integralista no Rio de Janeiro e também por fazer uma leitura da permanência das idéias integralistas a partir de organizações neointegralistas ${ }^{42}$, tema que até então não havia sido tratado até o presente momento. Outra importante contribuição para o debate foi a tese de doutoramento de Rosa Cavalari ${ }^{43}$, que apresenta a sistematização da estrutura de imprensa criada pela AIB e também a questão da simbologia e dos ritos integralistas (aqui entram pontos importantes como a imagem da mulher e da criança, por exemplo).

A questão do integralismo e os trabalhadores em São Paulo é o tema trabalhado por Renato Dotta ${ }^{44}$. Trabalha pontualmente cada profissão, fazendo análise dos materiais encontrados no jornal Ação.

Abordamos em nossa dissertação de mestrado, a questão do anticomunismo integralista presente nos jornais, revistas e livros de autores integralistas, buscando compreender como chegava ao militante

${ }^{39}$ CYTRYNOWICZ, Roney. Integralismo e antissemitismo nos textos de Gustavo Barroso na década de 30. São Paulo: USP, 1992 (dissertação de mestrado em História).

${ }^{40}$ MAIO, Marcos Chor. Nem Rotschild nem Trotsky: o pensamento antissemita de Gustavo Barroso. Rio de Janeiro: Imago, 1992.

${ }^{41}$ CARNEIRO, Márcia Regina da Silva. Memória e Integralismo: um estudo da militância no Rio de Janeiro. Niterói: UFF, 2000 (dissertação de mestrado em História).

${ }^{42}$ A autora não utiliza esse termo no texto, essa é uma livre interpretação nossa a partir de seu texto. Qualquer responsabilidade deve ser creditada a nós, não à autora.

${ }^{43}$ CALIL, Gilberto Grassi. O integralismo no pós-guerra: a formação do PRP (1945-1950). Porto Alegre: EDIPUCRS, 2001.

${ }^{44}$ DOTTA, Renato Alencar. O integralismo e os trabalhadores: as relações entre a AIB, os sindicatos e os trabalhadores através da imprensa integralista (1932-1938). São Paulo: USP, 2003 (dissertação de mestrado em História). 
esse anticomunismo e quais eram os interesses e objetivos por detrás do combate ao "inimigo vermelho". ${ }^{45}$

Outro tema que ganhou importância dentro das discussões foi o integralismo no pós-guerra. O trabalho pioneiro foi a dissertação de mestrado de Gilberto Calil. ${ }^{46}$ Aborda a reestruturação do integralismo em partido político, o Partido de Representação Popular. Tendo como marco temporal o período entre 1945 a 1950, apresenta em seus sete capítulos os elementos de gênese do partido no conturbado período de redemocratização, a estruturação interna do partido, seus projetos políticos e seus mecanismos de mobilização popular, o anticomunismo e a intervenção do PRP no processo político brasileiro entre 1945 e 1950. Outro trabalho que tem no PRP seu objeto é a dissertação de Claudira Cardoso, ${ }^{47}$ sobre as alianças políticas do partido no Rio Grande do Sul de 1958 e 1962. O trabalho lança luz sobre a atuação política do PRP e o seu papel de "fiel da balança" no jogo eleitoral sul-riograndense. Permite ter uma nova visão sobre a política no Estado, tendo em vista que os estudos geralmente apontam para uma polarização entre duas das principais forças políticas da época, PSD e PTB, não sobrando espaço para as forças menores. O trabalho de Cardoso mostrou o contrário, que os pequenos partidos tiveram papel decisivo (pelo menos nas eleições analisadas pela autora) e a necessidade dos dois pólos em atrair essas pequenas agremiações, faziam com que tivessem possibilidade de acesso a cargos do governo, fossem no primeiro, segundo ou terceiro escalões. Outro que aborda o integralismo no pós-1945 é o de Rodrigo Cristofoletti, que tem seu foco principal na edição da Enciclopédia do Integralismo. ${ }^{48}$

O integralismo nos anos 1960 no Rio Grande do Sul é trabalhado por Ângela Flach. ${ }^{49}$ Este trabalho faz uma interessante análise da participação dos perrepistas na política gaúcha em um dos momentos

45 OLIVEIRA, Rodrigo Santos de. Perante o tribunal da História: o anticomunismo da Ação Integralista Brasileira (1932-197). Porto Alegre: PUCRS, 2004 (dissertação de mestrado em História).

${ }^{46}$ CALIL, Gilberto Grassi. O integralismo no pós-guerra: a formação do PRP (1945-1950). Porto Alegre: EDIPUCRS, 2001.

${ }^{47}$ CARDOSO, Claudira do Socorro Cirino. Partido de Representação Popular: política de alianças e partidos nos governos estaduais do RS de 1958/1962. Porto Alegre: PUCRS, 1999 (dissertação de mestrado em História).

${ }^{48}$ CRISTOPHOLETTI, Rodrigo. As celebrações do jubileu de prata integralista (19571961). Assis, Faculdade de Ciências e Letras UNESP, 2002 (dissertação de mestrado em História).

${ }^{49}$ FLACH, Ângela. "Os vanguardeiros do anticomunismo”: o PRP e os perrepistas no RS (1961-1966). Porto Alegre: PUCRS, 2003 (dissertação de mestrado em História). 
de maior efervescência política da história republicana. Acompanha desde a atuação do PRP no governo de Leonel Brizola e seu rompimento a partir da Campanha da Legalidade, a articulação para a eleição de Ildo Meneghetti. Aborda o anticomunismo e a participação dos perrepistas no pré-março de 1964, além do PRP no novo contexto "revolucionário" e com o AI-2, que extinguiu as agremiações políticas, em outubro de 1965, e a atuação dos membros do PRP na ARENA.

Poderíamos expor ainda uma série de trabalhos realizados ou ainda em andamento nesses moldes. Cremos que seja desnecessário, pois a razão desse resgate não é o de fazer um levantamento exaustivo de pesquisas, mas traçar um pequeno histórico do interesse acadêmico sobre o tema.

\section{Apontamentos Finais}

O estudo sobre o integralismo atualmente ocupa um lugar de destaque dentre as temáticas desenvolvidas nas Ciências Humanas. Quantos temas já geraram debate acadêmico tão intenso, tão diversificado e com pesquisas em tantas partes do país? Raramente se encontra um estado brasileiro que não tenha pelo menos uma pesquisa sobre o integralismo. O objetivo desse resgate não é apresentar um suposto arrolamento completo sobre o tema, longe disso, quer mostrar a sua importância, que já foi debatida na Ciência Política, na História, na Sociologia, na Filosofia, na Literatura e na Educação, ao longo de mais de trinta anos. Grande parte dessas pesquisas apresenta um pequeno resgate bibliográfico. Contudo, levantam apenas questões relevantes aos seus estudos - o que não constitui problema algum nisso -, mas não se preocupam em explicitar a evolução do tema central de suas pesquisas: o integralismo, quer dentro do período da AIB, no pós-guerra ou no pós-1964. Por isso procuramos dar conta desse levantamento neste artigo com o objetivo de sistematizar tais obras e também auxiliar os pesquisadores que se preocupam com este objeto de estudo.

\section{Referências}

ARAÚJO, Ricardo Benzaquen de. Totalitarismo e Revolução. O integralismo de Plínio Salgado. Rio de Janeiro: Jorge Zahar, 1988.

BARRERAS, Maria José Lanziotti. Dario de Bittencourt (1901-1974): uma incursão pela cultura política autoritária gaúcha. Dissertação (Mestrado em História) - Pontifícia Universidade Católica do Rio Grande do Sul, Porto Alegre, 1993. 
BRANDALISE, Carla. O fascismo na periferia latino-americana: paradoxo da implantação do integralismo no Rio Grande do Sul. Dissertação (Mestrado em Ciência Política) - Universidade Federal do Rio Grande do Sul, Porto Alegre, 1992.

CALDEIRA, João Ricardo de Castro. Integralismo e política regional: a Ação Integralista Brasileira no Maranhão. São Paulo: Annablume, 1999.

CALIL, Gilberto; SILVA, Carla (Orgs.). O Integralismo brasileiro: história e caráter do movimento fascista no Brasil. Tese (Doutorado de Carlos Henrique Hunsche [autorizada pela Faculdade de Filosofia da Universidade Wilhelm, Berlim, 1930]). Tradução de Leandro Silva Teles. Porto Alegre, CD-AIB/PRP, 1996.

CALIL, Gilberto Grassi. O integralismo no pós-guerra: a formação do PRP (19451950). Porto Alegre: EDIPUCRS, 2001.

CANABARRO, Ivo dos Santos. Uma abordagem cultural de um movimento político dos anos trinta: o caso do integralismo em Ijuí. Dissertação (Mestrado em História) Universidade Federal do Rio Grande do Sul, Porto Alegre, 1994.

CARDOSO, Claudira do Socorro Cirino. Partido de Representação Popular: política de alianças e partidos nos governos estaduais do RS de 1958/1962. Dissertação (Mestrado em História) - Pontifícia Universidade Católica do Rio Grande do Sul, Porto Alegre, 1999.

CARNEIRO, Márcia Regina da Silva. Memória e Integralismo: um estudo da militância no Rio de Janeiro. Dissertação (Mestrado em História) - Universidade Federal Fluminense, Niterói, 2000.

CAVALARI, Rosa Maria Feiteiro. Integralismo: ideologia e organização de um partido de massa no Brasil (1932-1937). Bauru: EDUSP, 1999.

CRISTOPHOLETTI, Rodrigo. As celebrações do jubileu de prata integralista (19571961). Dissertação (Mestrado em História) - Faculdade de Ciências e Letras, UNESP, Assis, 2002.

CYTRYNOWICZ, Roney. Integralismo e antissemitismo nos textos de Gustavo Barroso na década de 30. Dissertação (Mestrado em História) - Universidade de São Paulo, São Paulo, 1992.

DOTTA, Renato Alencar. O integralismo e os trabalhadores: as relações entre a AIB, os sindicatos e os trabalhadores através da imprensa integralista (1932-1938). Dissertação (Mestrado em História) ) - Universidade de São Paulo, São Paulo, 2003.

FLACH, Ângela. "Os vanguardeiros do anticomunismo": o PRP e os perrepistas no RS (1961-1966). Dissertação (Mestrado em História) - Pontifícia Universidade Católica do Rio Grande do Sul, Porto Alegre, 2003.

GERTZ, René. O fascismo no sul do Brasil. Germanismo, nazismo, integralismo. Porto Alegre: Mercado Aberto, 1987.

GERTZ, René. Os Teuto-Brasileiros e Integralismo no Rio Grande do Sul. Contribuição para a interpretação de um fenômeno politico controvertido. Porto Alegre: UFRGS, 1977.

GIRON, Loraine Slomp. As Sombras do Littorio: o fascismo no Rio Grande do Sul. Porto Alegre: Parlenda, 1994.

GUT, Nicolau de Flue. Plínio Salgado, o creador do integralismo na literatura brasileira. Speyer a. Rh., Pilger-Druckerei GmbH, 1940.

IRSCHLINGER, Fausto Alencar. Perigo Verde: o integralismo no norte do Rio Grande do Sul (1932-1938). Passo Fundo: UPF, 2001. 
MAIO, Marcos Chor. Nem Rotschild nem Trotsky: o pensamento antissemita de Gustavo Barroso. Rio de Janeiro: Imago, 1992.

MILKE, Daniel Roberto. O integralismo na capital gaúcha: espaço político, receptividade e repressão (1934-1938). Dissertação (Mestrado em História) - Pontifícia Universidade Católica do Rio Grande do Sul, Porto Alegre, 2003.

MONTENEGRO, J.A.S. O integralismo no Ceará. Fortaleza, 1986.

OLIVEIRA, Rodrigo Santos de. Perante o tribunal da História: o anticomunismo da Ação Integralista Brasileira (1932-197). Dissertação (Mestrado em História) - Pontifícia Universidade Católica do Rio Grande do Sul, Porto Alegre, 2004.

PARENTE, Josênio. Os camisas verdes no poder. Fortaleza: Edições UFC, 1986.

PISTORELLO, Daniela. “Os homens somos nós”: o integralismo na região colonial italiana do Rio Grande do Sul. Dissertação (Mestrado em História) - Pontifícia Universidade Católica do Rio Grande do Sul, Porto Alegre, 2001.

TONINI, Veridiana M. Uma relação de amor e ódio: o caso Wolfram Metzler (19321957). Passo Fundo, UPF, 2003.

TRINDADE, Hélgio. Integralismo. O fascismo brasileiro da década de 30. Porto Alegre: DIFEL/UFRGS, 1974.

TRINDADE, Hélgio. Integralismo: teoria e práxis política nos anos 30. In: FAUSTO, Boris (Oorg.). História Geral da Civilização Brasileira - O Brasil Republicano, Sociedade e Política (1930-1964). São Paulo: DIFEL, 1981, vol. 3, p. 304-316. 